\title{
Recibimiento a Valeria Prado Jiménez en la Academia Chilena de Medicina*
}

\author{
Valeria Prado J.: New member of the Chilean Academy of Medicine
}

$\mathrm{L}$

a presentación de Valeria Prado Jiménez a la Academia de Medicina del Instituto de Chile constituye un cometido muy honroso pero no fácil de realizar. Esto último, por su impresionante curriculum que es muy difícil resumir sin cometer injusticias en cuanto a dejar de lado algunas facetas importantes de su quehacer.

La Dra. Prado es el paradigma de lo que las universidades desean de la formación de sus estudiantes: excelentes alumnos que continúan comprometidos con su alma mater, realizando una labor académica de relevancia que abarca las tres vertientes: docencia, investigación y extensión y que los llevan además a participar en la gestión universitaria, aportando inteligencia, buen juicio, experiencia y rigurosidad en todas sus actividades.

Hija de un funcionario público, que por razones de trabajo se movilizaba de una a otra ciudad, ella permaneció en Chillán, estudiando en el Liceo de Niñas. Recuerda con placer su época de Humanidades, como entonces se llamaba. Le gustaban todos los ramos pero ya tenía claro su interés por la investigación; encontraba excelente su colegio y sabía combinar muy bien el estudio con el baile y el folklore y disfrutaba con el ambiente cultural de su casa que era visitada por Violeta Parra y Pablo Neruda.

En $5^{\circ}$ año de Humanidades ( $3^{\circ}$ Medio actual) conoció en Tomé a Giorgio Bagoni, quien se convirtió en su marido seis años después. Desde entonces han mantenido una hermosa relación de compañerismo y amor que lleva ya 46 años y en que cada uno ha desarrollado con brillo sus respectivas profesiones: medicina y periodismo.

Fue considerada como la mejor alumna de toda la provincia de Ñuble por lo que le fue otorgada la Beca
Enrique Molina para estudiar en la Universidad de Concepción. Con esta beca gana independencia económica y decide entrar a estudiar Medicina, un poco a contrapelo de su padre que encontraba que esta profesión era poco femenina (después se convirtió en su fan número uno).

Aquí se empieza a manifestar otra de las características de Valeria: La libertad de su juicio y la independencia con que toma sus decisiones. En parte su modelo era su prima mayor; la Dra Cristina Palma, insigne figura de la medicina chilena, quien también llegara a ser miembro de la Academia en calidad de Honorario.

Sus cinco primeros años de la carrera los realiza en la Universidad de Concepción pero se traslada a la Universidad de Chile en Santiago a efectuar sus dos últimos años porque, ya casada con Giorgio, lo acompaña por razones laborales.

Sus compañeros la recuerdan como una excelente alumna, estudiosa, suave en su trato. Muy convencida de sus valores y consecuente en sus actitudes a pesar de considerarla tímida. Se hace de grandes amigos en la época universitaria.

No fueron años fáciles. Adaptarse al matrimonio, la llegada de los hijos: Gianfranco y Stefano, ingresar al postítulo, trabajar en el Servicio de Pediatría del Hospital Luis Calvo Mackenna, constituyeron un período de grandes desafíos y esfuerzos programados. Se recuerda con especial afecto del Profesor Jorge Howard, Jefe de Servicio de Pediatría en el Hospital Luis Calvo Mackenna quien la orientó y la entusiasmó con la idea de las becas mixtas. Considera su estada en "el Calvo" como la mejor experiencia de su carrera, por el entorno enriquecedor con excelentes especialistas con gran vocación por la docencia. Allí inició su investigación
*Sesión realizada el 16 de abril de 2009. 
clínica microbiológica y publica su primer trabajo sobre Salmonella Typhimurium.

La ida a su primer congreso, en Punta Arenas, significó una decisión: $\mathrm{Su}$ desarrollo profesional pasaba por establecer contactos y mostrar sus investigaciones, entrar a "la trenza de los científicos" como muy bien lo señala Giorgio. Así, recibió el apoyo irrestricto de su marido y de su madre y se sintió con la libertad de moverse por todo el mundo, como lo ha hecho, al principio con cierta dificultad, incorporando el inglés, viajando sola. Luego, cada vez con mayor soltura.

La familia completa se instaló en Italia por un año, en 1981, con una beca del Gobierno Italiano para perfeccionamiento en Enfermedades Infecciosas. Fue un año feliz: Todos se lo tomaron como un "semi-sabático" en que disponían en las tardes del tiempo suficiente para conocer y disfrutar de las artes y bellezas del Veneto.

Quisiera destacar aquí algo que me parece notable: La familia nunca ha considerado que esta vida profesional tan llena de actividades haya interferido con el hogar. Ella logra hacer una separación muy clara entre su casa y su trabajo: Nunca ha sacrificado un panorama de la familia por la preparación de sus publicaciones y conferencias y, aunque declara no saber cocinar, ha contado con personal eficiente, hijos con buena salud y se considera buena gerente de su casa.

Esto está destacando las más notables cualidades de Valeria: eficiencia, gran capacidad de trabajo y rendimiento que es fruto de la inteligencia, la programación, la persistencia y firmeza cuando decide realizar algo.

Sus colegas del Instituto de Ciencias Biomédicas (ICBM) de la Facultad de Medicina de la Universidad de Chile bien lo señalan: Frases refiriéndose a su fuerza, su claridad en búsqueda de objetivos académicos. Para otros, es una mujer de opiniones agudas y fundamentadas que tienden a cautelar la calidad académica y la han llevado a formar parte del núcleo duro del Instituto.

Sus colaboradores destacan su compromiso con la Facultad de Medicina y el ICBM, su capacidad ejecutiva, su estrictez en el manejo administrativo. A muchos su actitud les recuerda a los profesores de la vieja escuela, que inspiraban respeto por sus conocimientos y su honestidad.

Por sus logros científicos, Valeria ha recorrido el mundo: Desde 1990 ha participado en más de 150 congresos o reuniones de su especialidad, la mayoría internacionales, que la han llevado a distintos países de América del Sur y Central, 14 veces a E.U.A. y Canadá, Australia, a numerosos países de Europa, África y Asia (Japón, China, Filipinas, India).

Deliberadamente no he ocupado la frase: "asistido a congresos"; siempre ha participado activamente, llegando a presentar hasta 10 trabajos por congreso, ganando premios, dirigiendo sesiones, organizando actividades. Debemos hacer notar que la investigación de Valeria se ha realizado mayoritariamente en Chile, con todas las dificultades adicionales que esta decisión puede haberle significado y que hace valorar aún más la cuantía y calidad de su trabajo.

Esta impresionante representación del quehacer microbiológico e infectológico efectuado en nuestro país ha sido posible porque en forma sistematizada, programada, rigurosa, Valeria y su equipo de investigadores han desarrollado tres líneas de investigación prioritaria:

- Investigación básico-clínica en infecciones entéricas bacterianas, especialmente en relación a Escherichia coli enterohemorrágica, estudiando aspectos moleculares y desarrollando nuevas técnicas de diagnóstico.

- Su segundo polo de interés ha sido la evaluación de nuevas vacunas, en colaboración con el Centro para Desarrollo de Vacunas de Maryland (E.U.A., Myron Levine), especialmente para Vibrio cholerae y Streptococcus pneumoniae.

- La tercera línea de trabajo se ha referido a los antimicrobianos, realizando vigilancia de resistencia antimicrobiana en diferentes cuadros clínicos, mediante red de laboratorios, estudiando los mecanismos moleculares de esta resistencia y realizando estudios clínicos para evaluar la eficacia y seguridad de antimicrobianos.

Como se puede apreciar, ha incursionado en la investigación pura y en la investigación aplicada, lo que le ha permitido obtener 52 grants nacionales y extranjeros que han equipado su laboratorio y publicar 179 trabajos con sus excelentes colaboradores y discípulos.

$\mathrm{Su}$ paso por 141 reuniones nacionales e internacionales ha sido reconocido, nombrándosela miembro de 10 sociedades científicas, huésped ilustre de variadas ciudades, Miembro notable de la Sociedad Latinoamericana de Infectología Pediátrica, con la cual ha colaborado desde su fundación, habiendo recibido 20 premios.

Actualmente continúa con su ritmo incansable de trabajos y viajes, formando parte de dos proyectos multinacionales de gran trascendencia: Desde hace tres años, bajo la coordinación de la Universidad de Maryland, su laboratorio forma parte, como centro de referencia, de un estudio epidemiológico en agentes de diarrea causantes de mortalidad que incluye ocho países subdesarrollados, cinco africanos y tres asiáticos.

Con la Comunidad Económica Europea forma parte 
del Pathogenic Escherichia coli Network (sólo Chile fuera de Europa) con coordinación en Irlanda.

Uno se podría preguntar: ¿Se ve a Valeria abrumada por todas estas responsabilidades? Para nada. Siempre tranquila, discreta, elegante, contribuyendo a la realización de sus colaboradores y de su familia. La vida por delante tiene al grupo familiar lleno de proyectos entre los que se destacan los viajes ya que todos están contaminados con esa resistente bacteria...

Cuando uno le pregunta a Valeria quiénes han sido modelos en su vida profesional, no duda en nombrar a Jorge Howard, a Alejandro Goic y a Cristina Palma.

Todos ellos tienen en común, rigurosidad en su quehacer, gran capacidad de decisión ante dificultades y evidente liderazgo. Valeria comparte estas carac- terísticas y significa indudablemente un ejemplo -reconozcamos difícil de seguir- para todos los profesionales del país. En todos los casos señalados, ellos han devuelto con creces lo que el Estado invirtió en su formación.

La Academia de Medicina no puede sino sentirse orgullosa y complacida en recibir a Valeria Prado como Miembro de Número y está segura de que contará con una colaboradora de excelencia en el logro de su misión.

¡Bienvenida, Valeria!

Colomba Norero $V$., Miembro de Número. Academia de Medicina, Instituto de Chile.
Valeria Prado, fundación y desarrollo de la Sociedad Chilena de Infectología

Cuando un grupo de colegas tomó la iniciativa de reunirse a discutir la fundación de una Sociedad Científica que agrupara a los médicos que se interesaban por las enfermedades infecciosas del niño y del adulto, más los microbiólogos clínicos, apareció Valeria Prado. Ella había sido informada por Manuel Rodríguez Leiva de este grupo, sus intenciones y el lugar de la convocatoria.

De inmediato, Valeria tomó protagonismo, informándonos que en Guadalajara, México, se había reunido un conjunto de colegas latinoamericanos y fundado la Asociación Panamericana de Infectología (API). Por primera vez surgía la palabra Infectología en vez de la traducción literaria del inglés, que hubiese sido Enfermedades Infecciosas. Los más académicos de la lengua en ese grupo (Drs. Jiménez, Salcedo y Herrera) concordaron que la palabra en español era Infectología.

Los estatutos de la API junto a los vigentes en la Sociedad Chilena de Pediatría sirvieron de base para la redacción de nuestros propios estatutos.

Valeria fue, por supuesto, miembro del primer directorio de la SOCHINF y entusiasta participante de los congresos y cursos que organizamos.

Fue también ella quien apoyó con entusiasmo la creación de "Revista Chilena de Infectología", la que comenzó a publicarse sólo un año después de fundarse la Sociedad (año 1984). Soy testigo de primera línea para reconocer que el apoyo dado por Valeria y su grupo, enviando trabajos originales, revisiones y otro tipo de material, permitió que la revista pudiera mantener su publicación periódica, ya que en esos años era muy difícil conseguir artículos.

Ella también fue la principal defensora de que no se cambiara al Editor de la revista sino que se mantuviera por un período prolongado, dando la continuidad a la publicación.

Con respecto a API, ella era el referente en Chile y propugnó la incorporación de muchos de nosotros y participar en la Asociación. Fue así como después de Perú conseguimos que el Congreso Panamericano de Infectología (año 1993) se realizara en Chile. Teniendo ella todas las condiciones y méritos para haber sido la presidenta de dicho evento, prefirió dar un paso al costado para que otro tomara esa responsabilidad y fuera el Presidente de API después de realizado el Congreso. Sin embargo, ella fue la Secretaria Ejecutiva de ese congreso, de gran recuerdo para la Infectología chilena y luego aceptó seguir siendo la secretaria de API, contribuyendo grandemente al éxito de nuestra gestión.

Valeria fue la cuarta Presidente de la SOCHINF, primera mujer en el cargo y en nuestra sociedad ha sido una continua participante en todo tipo de responsabilidades, brillando en todas ellas.

Es también fundadora de la Sociedad Latinoamericana de Infectología Pediátrica (SLIPE).

Sin duda, es un ejemplo y modelo para muchos de nosotros, por lo que nos alegramos enormemente que haya sido electa como miembro de número de la Academia Chilena de Medicina donde, con toda seguridad, contribuirá con brillo al engrandecimiento de ella.

Guillermo Acuña L. Editor Emérito Revista Chilena de Infectología 